\title{
DISCLAIMER
}

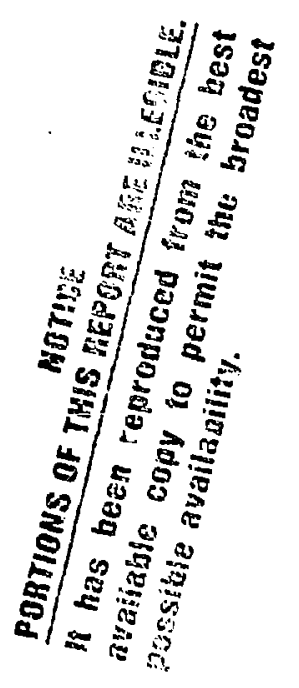

This report was prepared as an account of work sponsored by an agency of the United States Government. Neither the United States Government nor any agency thereof, nor any of their employees, makes any warranty, express or implied, or assumes any legal liability or responsibility for the accuracy, completeness, or usefulness of any information, apparatus, product, or pr scess disclosed, or represents that its use would not infringe privately owned rights. Reference herein to any specific commercial product, process, or service by trade name, trademark, manufacturet, or otherwise does not necessarily constitute or imply its endorsement, recommendation, or favorirg by the United States Government or any agency thereof. The views and opinions of authurs expressed herein do not necessarily state or reflect those of the United States Government or any agency thereof.

MULTIPHOTON IONIZATION OF ATOMIC CESIUM*

$\cos 10-0203: 7--13$

0565001250

by

R. N. Compton, C. E. Klots, J.A.D. Stockdale, and C. D. Cooper**

Oak Ridge National Laboratory

Oak Ridge, Tennessee 37831

\author{
Presented at \\ Topical Moeting on Laser Techniques in Ertreme U1traviolet \\ Boulder, Colorado, March 5-7, 1984
}

- Research sponsored by the Office of Health and Environmental Research,

U.S. Department of Energy .nder contract DE-AC05-840R21400

with Martin Marietta Energy Systems, Inc.

* Department of Physics, University of Georgia, Athens, GA 30601. 


\section{MULTIPHOTON IONIZATION OF ATOMIC CESIUM}

R. N. Compton, C. E. Klots, J.A.D. Stockdale, and C. D. Cooper

Oak Ridge Naíional Laboratory, Oak Ridge, Tennessee 37831

\section{ABSTRACT}

Fe describe experimental studies of resonantly enhanced multiphoton ionization (MPI) of cosing atoms in the presence and absence of an external electric field. In the zero-field studies, photoelectron angular distributions for one- and two-photon resonanty enhanced MPI are compared with the theory of Tang and Lambroponios. Deviations of experimont from theory are attributed to hyperfine coupling offects in the resonant intermediate state. The agreement between theory and experiment is excollont. In the absence of an external electric field, signal due to two-photon resonant threephoton ionization of cosium via np states is undetectable. Application of en electric fiold mixes nearby nd and ns levels, thoreby inducing excitation and subsequent ionization. Signal due to two-photon excitation of ns levels in field-free experiments is weak due to their small photoionization cross section. An electric field mixes nearby np levels which again allows detectable photoionization signal. For both ns and np states the "field induced" MPI signal increases as the square of the electric field for a given principal quantum number and increases rapidiy with $n$ for given field strength.

Finally, we note that the classical two-photon field-ionization threshold is lower for the case in which the laser polarization and the electric field are parallel than it is when they are perpendicular.

\section{INTRODUCTION}

Maltiphoton ionization (MPI) of alkali atoms has played a pirotal role in our understanding of the interaction of intense electromagnetic radiation with matter. The "hydrogen-1ike" energy levels and absence of low-1ying antoionizing states make the alkali atom theoretically tractablo. The low ionization potential and the ease with which one can prodnce atomic beams of alkali atoms facilitates the experimental studies. Many of the onrly MPI studies involved high-powered fixed-frequency lasers. Presently, the availability of tunable dye lasers with wavelength extension (i.e., frequency doubling, Raman shifting, otc.) makes it possible to study one- to six-photon ionization of the alkali atom with continuously tunable radiation. Also, hermonic generation in these systems which may be present during ionization can be recorded more easily than in other systems since the radiation generated is in the visible or

- Research sponsored by the Office of Health and Environmental Research, U.S. Department of Energy, under contract DE-AC05$840 R 21400$ with Martin Marietta Energy Systems, Inc.

- Department of Physics, Dniversity of Georgia, Athens, GA 30601. 
near ultraviolet opoctral rogion. The ability to tune the laser to high Rydberg atates using either oven or odd numbers of photons eccesses electronic states of both paritios. Stepwise oxcitation is capable of selectively producing states of high orbital angalar momentum.

The angular distributions of photosjected electrons provide valuable information about the itructure of atoms and molecules and the photoionization process itself. The photoelectron angular distributions depend upon the nature of the initial bound state and final continum states. The continuan contribution involves the interference between the partial waves of the outgoing electron, and any interaction between this electron and the ion core. The electron angular distribution resulting from the electric-dipole interaction between a cingle photon and an isotropic distribution of atoms is given by

$$
\frac{d \sigma(\lambda, \theta)}{d D}=\frac{\sigma_{\mathrm{TOT}}(\lambda)}{4 \pi}\left[1+\beta \mathrm{P}_{2}(\cos \theta)\right]
$$

where $\sigma_{\text {TOT }}$ is the generalized photoionization cross section for. one-photon ionization at wavelength $\lambda, P_{2}(\cos \theta)$ is the second Legendre polynomial, $\theta$ is the angle between the polarization axis of the incident light and the direction of the photoelectron $B$ and the value of $\beta$ is the so-called asymmetry parameter. $\beta$ can vary continuously from -1 to +2 .

In MPI, the order of the process (i.e., number of photons involved) snd the possible participation of real and virtual il Eermediate states are tho two most important factors which determine the angular distribution. For the case of nonresonant MPI or for resonantly enhanced MPI and when the laser intensity is weak enough to validate the lowest order perturbation theory, the generalized cross section for N-photon ionization can be written as

$$
\frac{d \sigma(\lambda, \theta)}{d \Omega}=\frac{\sigma_{\mathrm{TOT}}(\lambda)}{4 \pi} \sum_{i=0}^{N} \beta_{2 i} P_{2 i}(\cos \theta)
$$

where $P_{2} i(\cos \theta)$ is the 2 ith order Legendre polynominal of order $2 i$ and $\beta_{2}$ are functions of microscopic tomic parameters.

$\boldsymbol{Z}^{\mathrm{i}}$ number of theoretical atudies of angular distributions of photoelectrons from UPI have been published.1-5 L-perimental mensurements of angular distributions have been presented for twophoton ionization of sodium,6,7 of titanium, 8 of cesium, 9 of strontinm, 10 and five-photon (nonresonant) lonization of sodium.11 The influence of nuclear spin on angular distributions has been studied for the case of sodium.12 In addition, the effects of "quantum beats" due to the hyperfine levels on angular distributions have been observed.13 Fina11y, Edgalar distributions for so-called above threshold ionization of xenon at fixed wavelength $(0.53 \mu \mathrm{m})$ have been reported.14 Both the experimental and theoretical studies have illustrated that measurements of angular distributions of photoelectrons from resonant MPI are complicated by the following: 
1. The engular distributions may be laser power dependent due to sataration of ome resonant level or due to a.c. Stark effects on the ground and excited states involved, 4,15

2. So-called above threshold ionization 14,16 effects in which photoejected electrons gnin energy from the radiation field may complicate the measurements.

3. If more than one hyperfine level is excited (which is most often the case), "quantum beat" interference effects produce angular distributions which are dependent upon the temporal characteristics of the laser beam. For erample, in two-photon ionization, the photoelectron angular distribution for the two-photon ionization of sodium via the $3^{2} \mathrm{P}_{3} / 2$ state is found to depend apon the time delay between the exciting and ionizing laser polses. 13

4. Sometimes subtle background or surface ionization effects are observed which can interfere with (or even obscure) the real sigral (see, 0.g., Ref. 7).

The studies of photoabsorption in DC-olectric fields is a well developed subject. First-order stark shifts in bydrogen and second-order Stark shifts in other atoms have been erhaustively stadicd for the case of one-photon absorption. In this work we pressnt the first experimental studies of the DC Stark effect upon MPI. As we shall see, the DC Stark effect can greatly enhance the MPI cross section both in the resonant excitetion step and in the ionization s+ep.

Experirents in which highly excited states are produced in extermal electric or magnetic fields allow one to test fundamental ideas about the electron-Coulomb system in the quasi-continum.17 In this work re describe studies of MPI in the presence of an electric field $(E=5$ to $4000 \mathrm{~V} / \mathrm{cm})$ in which the plane of polarization of the laser can be rotated relative to the direction of the electric field. As we shall see. the Stark effect mixes nearby states of different parity, allowing for the detection of dipole forbidden states. Finally, re will show that the classical (two-photor) field ionization threshold is lower for the case when the laser polarization and the electric field are parallel than it is when hey are perpendicular.

\section{EXPERIMENTAL}

The MPI photoelectron sngular distributions were measured in an apparatus consisting of a collimated cesium beam which is directed into the entrance of double focusing spherical sector electron energy analyzer. A laser beam is focused to a spot $1 \mathrm{~cm}$ from the entrance hole. The acceptance angle is $\sim \pm 2^{\circ}$. The laser power density $13 \sim 10^{8} \mathrm{~W} / \mathrm{cm}^{2}$. Experiments involving the DC Stark effect on MPI vere performed in a parallei field geometry. The laser beam was focused berween two parallel plates separated by $\sim 0.6 \mathrm{~cm}$. The electric field conld be varied from 0 to $\sim 3 \mathrm{KV} / \mathrm{cm}$. Ions were pushed through a grid in the negative plate and detected with a dual channel plate charged particle detector after drifting through a short time-of-f1ight mass spectrometer $(-10 \mathrm{~cm})$. 
In both experiments, Molectron nodel UV-24 nitrogen laser ( 1 MW peak powor) was used to pump the oscillator and amplifior of a Molectron model DL-14 dye laser. Tho bandwidth of the laser was - 0.2 A (FWHM). A Glan-Air prism (Carl Lambrocht) was used to purify the Laser beam and the polarization was rotated through a full $2 \pi$ angle with one of two different Fresnel rhomb polarization rotators.

In both experiments tho laser ionization signal is processod with a Princeton Applied Research boxcax integrator model 165. Figure 1 shows a typical rocordor trace of the electron onergy spectrum for tiree of the resonant intermediate states reported herejn. The absolute energy scale was not ostablished. Excellent solf-consistency among all of the peaks was observed. That is, b; establishing an energy scale for one resonent intermediate level such as for the $\mathrm{Tp}^{2} \mathrm{P}_{3 / 2}$ state (as as done in Fig. 1), all other perks would correspond to the expected valuos [i.e., 2hv-IP (Cs) or $3 \mathrm{hv}$-IP (Cs)]. The best resolution obtaised in any of the alkali studies was $0.07 \mathrm{eV}$ with 0.1 to $0.2 \mathrm{eV}$ resolution commonly used.

\section{RESULTS AND DISCUSSION}

\section{A. Angular Distributions}

Figure 2 show s the iPI photoelectron angular distribution for the caso of two-photon lonization in which the first photon is in resonance with the $7 \mathrm{p}^{2} \mathrm{P}_{1 / 2}$ state of cesium. Since no orientation of the $7 \mathrm{p}^{2} \mathrm{P}_{1 / 2}$ state is expected from the transition $6 \mathrm{~s}^{2} \mathrm{~S}_{1 / 2}-27 \mathrm{P}_{1 / 2}$ the angular distributign will resemble one-photon distribution, i.e., $I(\theta)=1+\beta_{2} \cos ^{2} \theta$ The experimental data shown in Fig. 2 are not corrected for the finite angular resolution of the electron spectrometer $\left(\Delta \theta= \pm 2^{\circ}\right)$. The finite angular resolution was mathematically unfolded from all of the experimental dat in this work and the points in the unfolded distribution were almost indistinguishable from the original distribution. The difference in the two distributions was woll within the uncertainty in the measurements. Kaminski, Kessler, and Kollath18 have published angolar distributions for the same transition and these data are in good agreement with the date shown in Fig. 2. Tang and Lambropculos 19 have calculated angular distributions for the $7 p^{2} \mathrm{P}_{1 / 2}$ state according to the method of Dixit and Lambroponlos 20 and their calculations are shown as solid line in Fig. 2. There is excellont agreement between experiment and theory.

The angular distribution for photoionization of the $7 \mathrm{p}^{2} \mathrm{P}_{3} / 2$ state is shown in Fig. 3. In this case the agreement between theory and experiment is poor. Although the general features of the experimental data are predicted, the theory is always we11 belor the experimental points when normalized at $\theta=0$ and $\pi$. The previous data of Kaminsti, Kessler, and Kollath 18 in Fig. 4 shows even larger discrepancies. The rather large differences between the theory and the two conflicting oxperimental studies are believed to be due to the mixing of hyperfine levels in the $7 p^{2} \mathrm{P}_{3} / 2$ state. The splitting between the two extreme hyperfine levels of the $7 p^{2} \mathrm{P}_{3} / 2$ stato is 198 Mz which corresponds to a hyperfine period of 5 ns. Ont laser has 

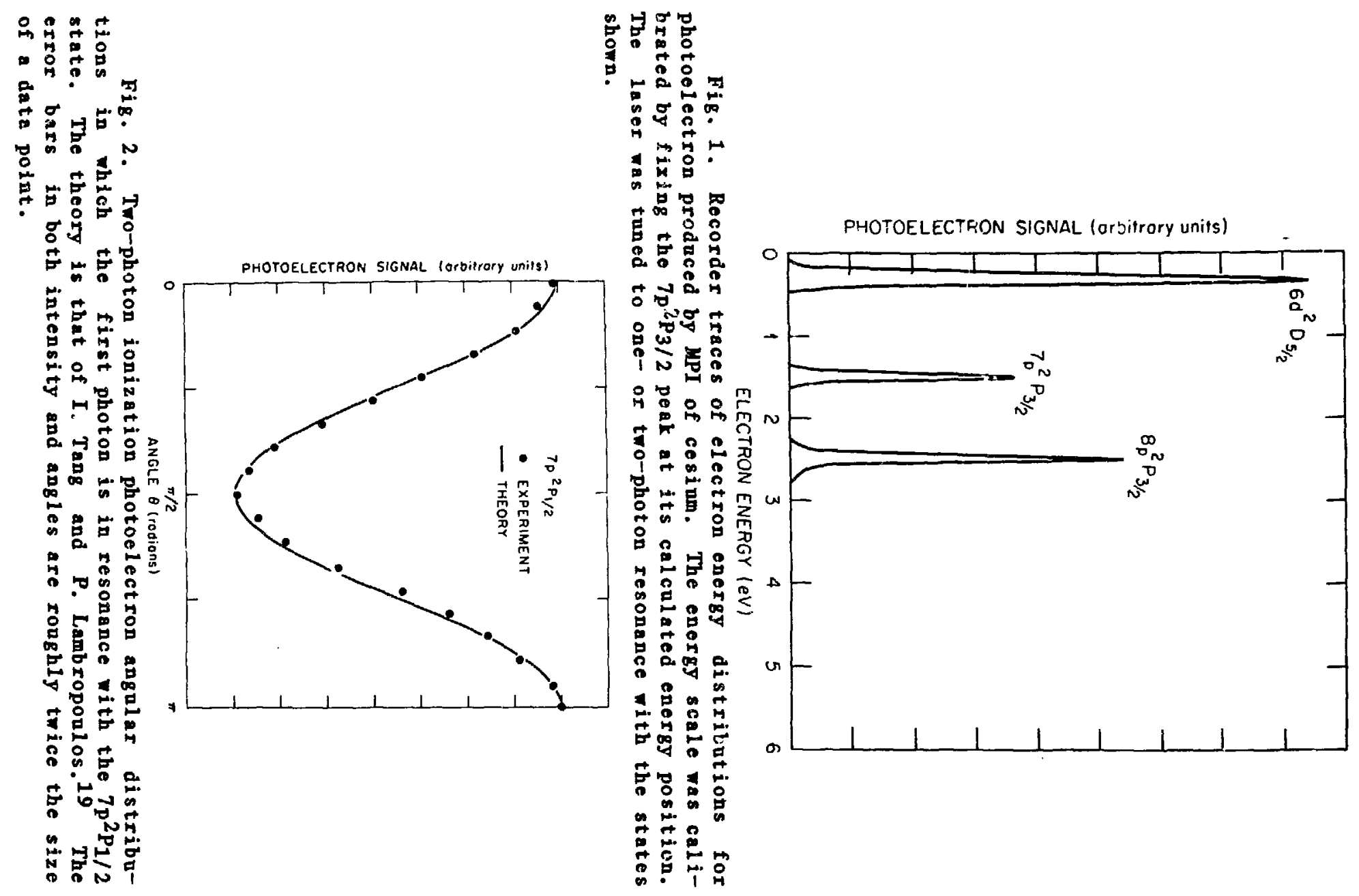


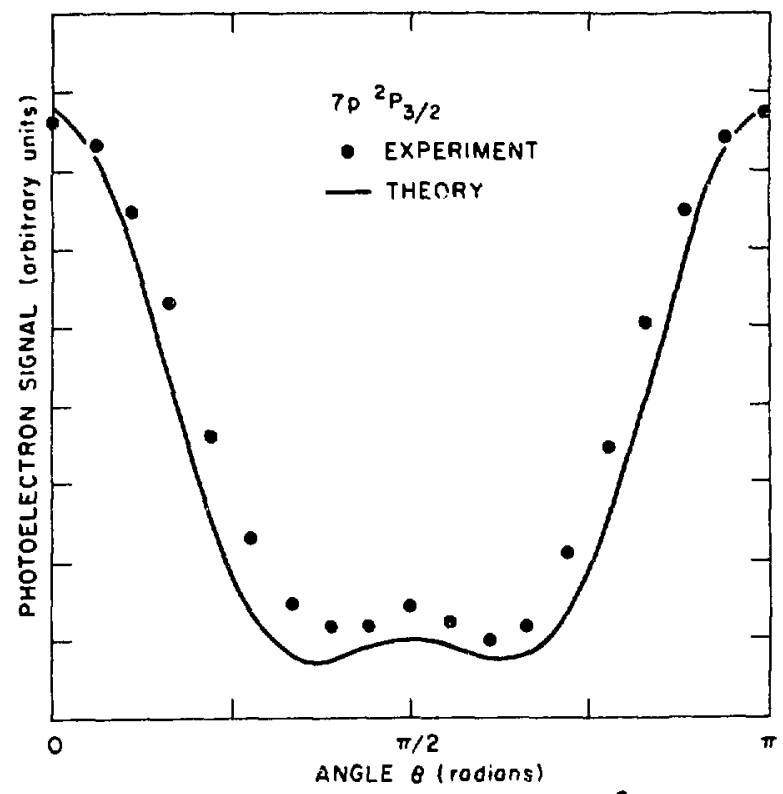

Fig. 3. Same as Fig. 2 except $7 \mathrm{p} 1 / 2 \rightarrow 7 \mathrm{p}^{2} \mathrm{P} / 2$ is also added. The slight difference in the two distributions is attributed to partical hyperfine mixing of the intermedite $7 \mathrm{p}^{2} \mathrm{P} 3 / 2$ level during the $10 \mu s$ laser polse. Theory is due to Tang and Lambropoulos.19

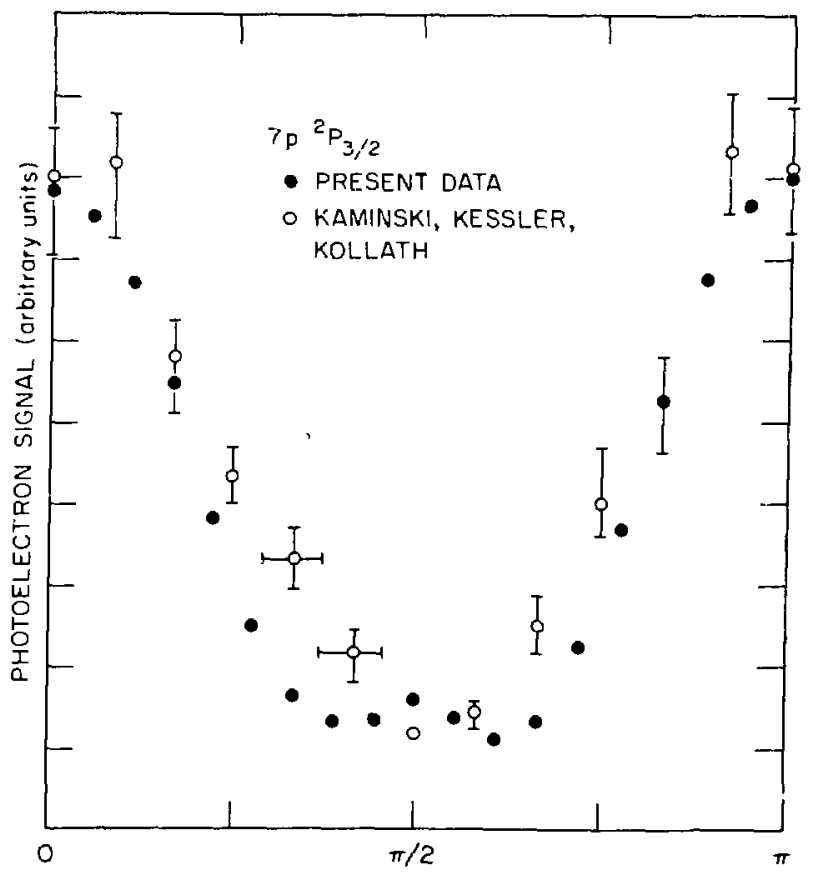

ANGLE $\theta$ (radions)

Fig. 4. Comparison of previous data [Kaminski, Kessler, and Kollath (KKR) $]^{9}$ with the present data for the $7 p^{2} \mathrm{P}_{3} / 2$ state. The 1 aser pulse width for the data of KKK is 4400 ns. The difference two sets of experimental in the data is attributed to complete hyperfine mixing during the laserpalse in the case of KKK. Theory is due to Tang and Lambropoulos. 19 
a pulse daration of $\sim 10$ ns which would allow for some hyperfine mixing during the cxcitation-ionization event. The flashlemp pamped laser of Kamineli, Kessler, and Kollath18 had palse length of 400 ns allowing for complete mixing of the hyperfine levels thus producing the distribution shown in Fig. 3. The lyyperfine period for the $8 \mathrm{p}^{2} \mathrm{P}_{3 / 2}$ stute is about twice os long as thet for the $7 \mathrm{p}^{2} \mathrm{P}_{3 / 2}$ and thererore we should expect better agreement between experiment and theory. Figures 5 and 6 show the experimental and theoretical results for the $8 \mathrm{p}^{2} \mathrm{Pl}_{1 / 2}$ and $8 \mathrm{p}^{2} \mathrm{P}_{3 / 2}$ states, respectively. The results forther illustrate the effect of hyperfine coupling, i.e., the agreement for the $8 \mathrm{p}^{2} \mathrm{P}_{1} / 2$ state where no crientation occurs is exc-11ent, whereas the thoory for the $8 \mathrm{p}^{2} \mathrm{P}_{3 / 2}$ again falls below the data.

Figure 7 show the experimental angular distribution for the case of two-photon resorant three-photon ionization of cesiam via the $8 \mathrm{~d}^{2} \mathrm{D} 5 / 2$ intermediare siate. Here the hyperfine period is $\sim 55 \mathrm{~ns}$ and the agreement between theory and experiment is good. In this case the laser pulse is over before hyperfine ccupling can occur.

Tang and Lambropoulosi9 have developed theoretical expression which takes into account the hypirfine effects on ihe anguiar distributions for the $7 \mathrm{p}^{2} \mathrm{P}_{3} / 2$ and $8 \mathrm{p}^{2} \mathrm{~F} 3 / 2$ resonent intermodiate state. The theory satisfactorily accounts for the distributions presented in Figs. 3 and 4 and the data of Ref. 9.

\section{B. Field Effocts on Mpltiphoton Iorization}

In these experiments an effusive atomic beam is crossed at right angles by tunable light from a nitrogen laser-pumped dye laser. Perpendicular to both beams, a variable, uniform electric field draws sny resulting positive ions through time-of-flight mass spectrometer into channelplate charged particle detector. The angle $\theta$ between the applied electric field $\vec{F}$ and the electric vector $\vec{E}$ of the laser beam is also continuously variable using a donble Fresnel rhomb rotator.

As Fig. 8 iilustrates, the MPI signal at low electric fields is greatly enhanced when the second photon is resonant with a ndevel. The MPI signal is seen to drop rapidly with increasing principal quantam number $\left(\sim 1 / n^{8}\right)$, mainly due to the fact that the photoabsorption $\left(\sim 1 / n^{3}\right)$ and photoionization $\left(\sim 1 / n^{5}\right)$ cross soctions are decreasing rapidy with $n$. The signal reappears as an approximate "step function" where a third photon is no longer necessary to effect ionization. As illustrated, this step occurs below the zero-field two-photon ionization potential. The shift $\Delta$ from the true $I P$, as a function of the electric field, F follors closely the familiar relation for field ionization:

$$
\Delta=a|\vec{F}|^{1 / 2}
$$

with $\Delta$ and $|\vec{F}|$ in atomic onits, and $\vec{E}$ parallel to $\vec{F}$ we find a $=$ $1.90( \pm 0.03)$, close to the semi-classical value of 2 . Upon rotating $\vec{E}$ perpendicalar to $F$, the ionization threshold shifts to lower energy, consistent with the classical model of Cook and Gallagher.21 


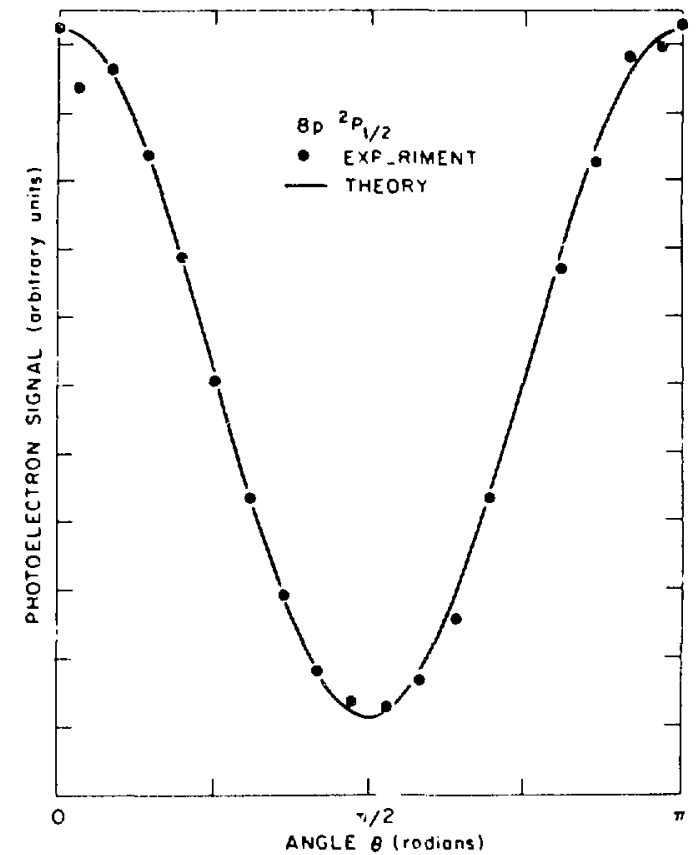

Fig: 5. Same as Fig. 2 except with the $8 \mathrm{p}^{2} \mathrm{P}_{1 / 2}$ state.

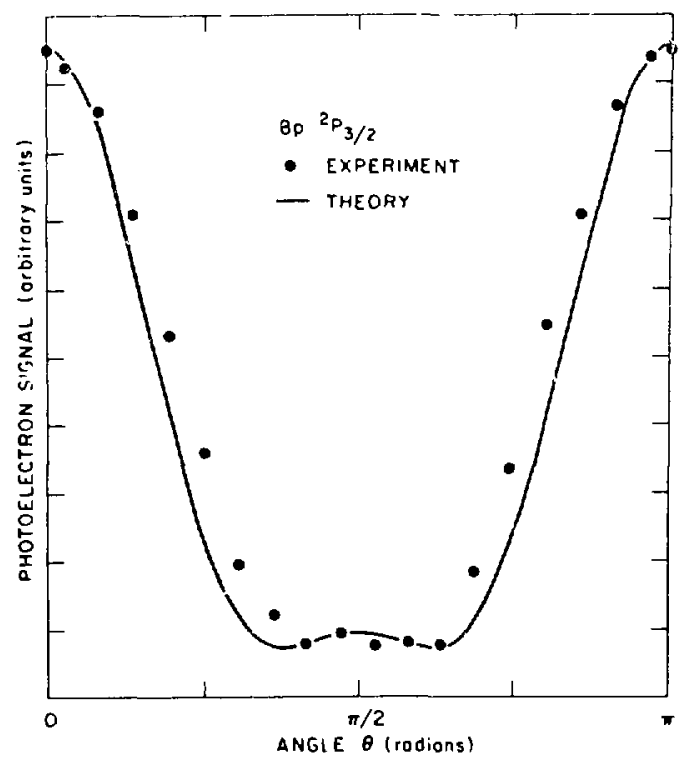

Fig. 6. Same as Fig. 3 except with $8 p_{1 / 2} \rightarrow 8 p^{2} p_{3 / 2}$. 


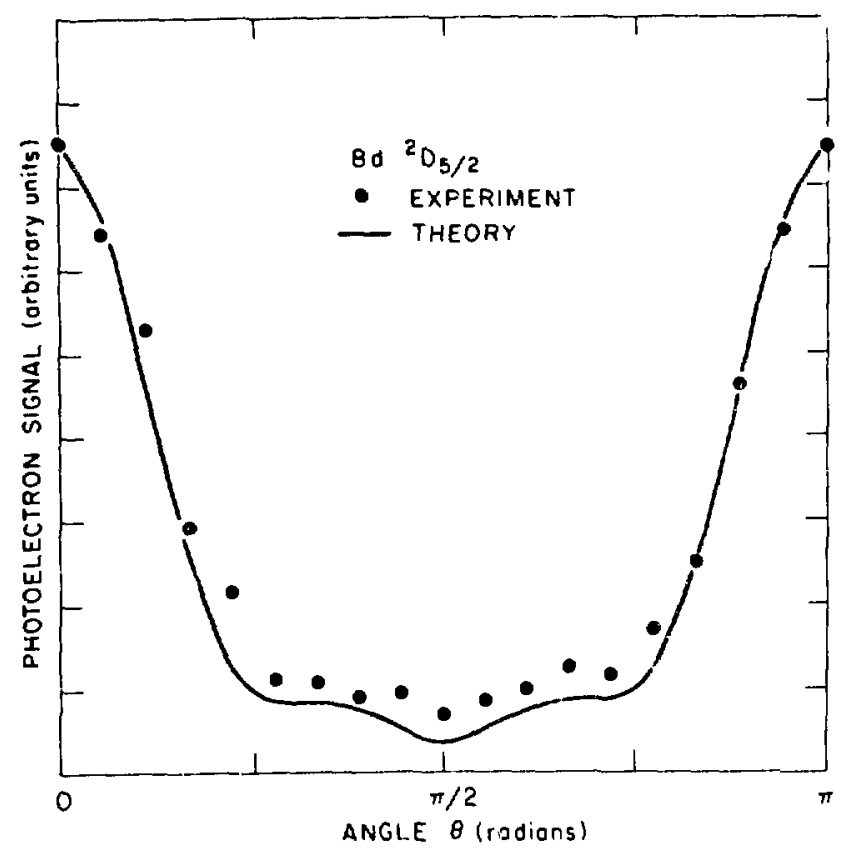

Fig. ?. Samp as Fig. 2 except with the $8 d^{2} D_{5 / 2}$ state.

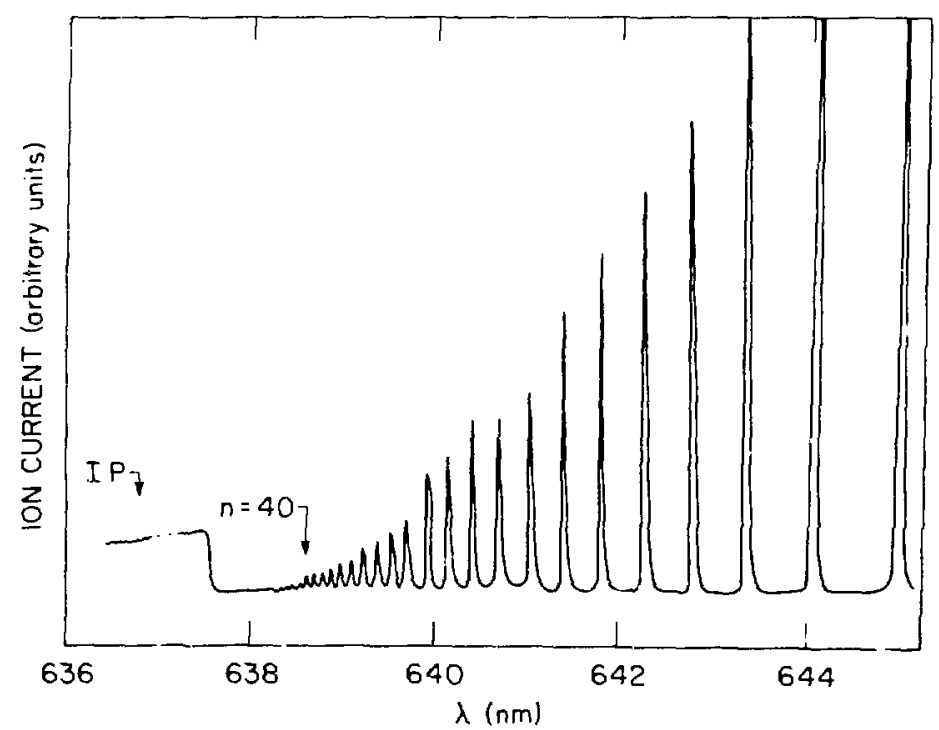

Fig. 8. Maltiphoton ionization signal near the two-photon ionization threshold at $636.8 \mathrm{~nm}$. The sharp peak represent twophoton resonent (nd leve1) three-photon ionization. The tro-photon ionization "step" is observed below the zero field value at 636.8 due to field lonization. 
For very low ion draw-out fields ( $10 \mathrm{v} / \mathrm{cm})$, wak signals are observed at the laser wavelength corresponding to two-photon excitation, three-photon ionization via the tro-pbuton allowed ns levels. A component of the ns signal is seer tr, increase as the square of the electric field. Fe find for $R[1 \mathrm{~s} /(n-1) d]$, the ratio of MPI strength via as as state to that vin the (n-1) d5/2 state:

$$
R\left[n s /(n-1) d_{5 / 2}\right]=\gamma_{0}+\gamma(n s)|\vec{F}|^{2}
$$

where $\gamma_{0}$ is less than 0.01 and where the coefficient $\gamma$ is a strongly increasing function of $n$. We interpret this as follows: tro-photon excitation oscillator stzagths for ns and nd series are comparable. The cross section for subsequent photoionization of an as tate is expected to be quite sins11. For example, Pindzola (private communication) calculates the photoionization cross secticn for the $8 \mathrm{~s}$ state to be $\sim 4 \times 10^{-4}$ times smaller than the $8 \mathrm{~d} 3 / 2$ state and the $12 \mathrm{~s}$ state to be $8 \times 10^{-3}$ times smallor than the $12.3 / 2$ state. An electric field inixes in the nearby np levels and it is this component of the Stark mized state which is more readily photoionized. Figure 9 shows the field-induced signal at the $16 \mathrm{~s}$ enerby level. The effective quantum number is 12 (quentum defect = 4) and therefore 9 other higher angalar momentum states are soen (one is hidden under the 168 signal). The remaining 12d and 12p states are not shown.

Field-induced MPI is also readily distinguished from a fieldfree component via its dependence on the angle between $\bar{E}$ and $\vec{F}$. Te find

$$
\gamma(n s) \sim 1+0.8 \cos ^{2} \theta
$$

Increasing the electric field also permits normally forbidden MPI via the np series, but for complementary reason. The field mixes a p state with nearby or d level, farmitting two-photon access to the p series. Photoionization of the original p component then ensues. We show a typical field-induced np level in Fig. 10 for $n=$ 13. The ratio of the $p$ levels to the adjacent d levels follows:

$$
\mathrm{K}\left(n \mathrm{P}_{\mathrm{J}} /(\mathrm{n}-1) \mathrm{d}_{5 / 2}\right)=\gamma\left(\mathrm{np}_{\mathrm{J}}\right)|\overrightarrow{\mathrm{F}}|^{2}
$$

consistent with the proposed mechanism. The coefficient $\gamma\left(n_{3} / 2\right)$ is a rapidy increasing function of principal quantum number. $3 / 2$ is also function of $\theta$ as show in Fig. 11. Te find

$$
\gamma(n p) \sim 1+0.55 \cos ^{2} \theta+2.66(\sin \theta \cos \theta)^{2}
$$

and, for the ratio of spin-orbit components, $\gamma\left(\mathrm{np}_{3 / 2}\right) /$ $\gamma\left(r \mathrm{p}_{1 / 2} \simeq 4.5( \pm 0.5)\right.$. This ratio, while not statistical is closer to the value 2 than the anomolousiy high values observed in onephoton absorption oscillator strengths. 22

The relations reported here were obtained at sufficiently low electric fields that perturbation thoory should still be valid. At higher îlds we observe large-scale level shifts and the emergence 


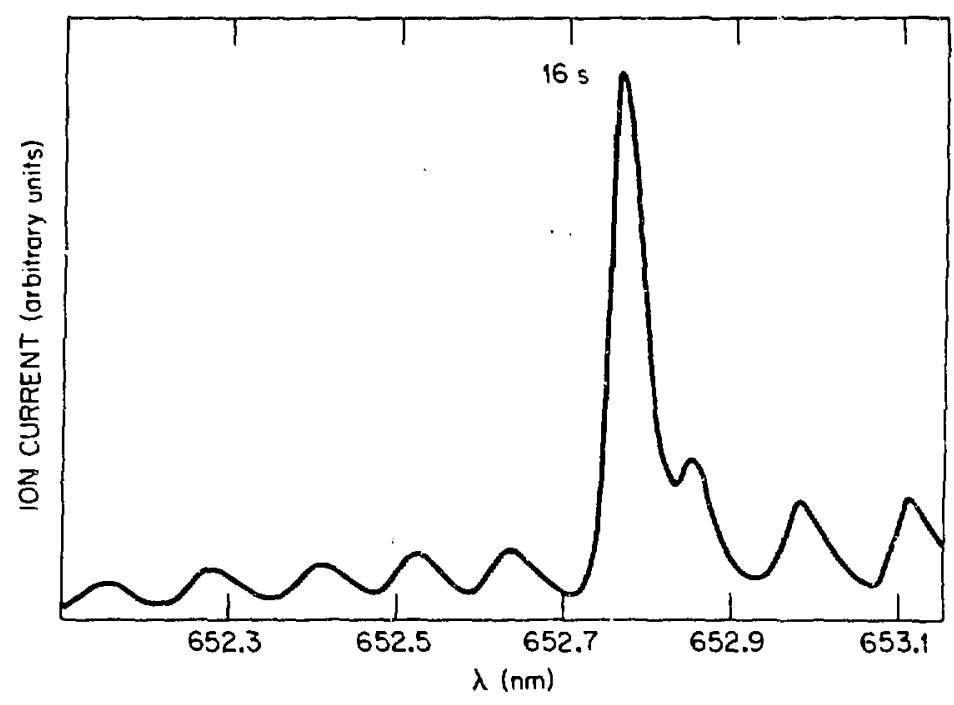

Fig. 9. Electric field enhanced three-photon ionization of $n \ell$ states of cesium noar the $16 \mathrm{~s}$ level. Fieid strength $3500 \mathrm{~V} / \mathrm{cm}$.

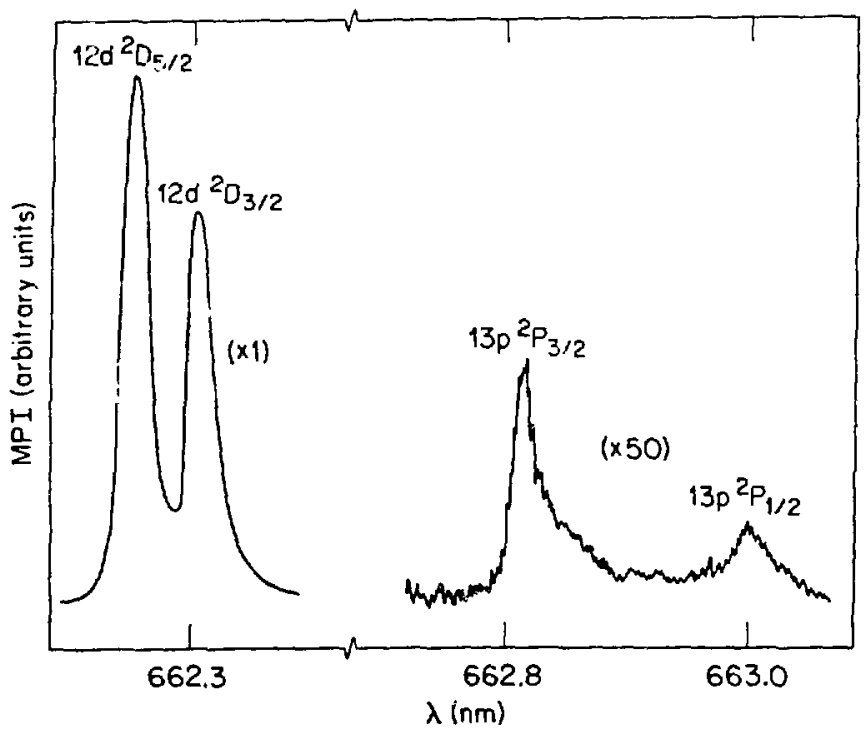

Fig. 10, Electric field induced tzsee-photon ionization of itomic cesium in which the second photon is in resonance with the $1 \mathrm{P}^{2} \mathrm{P}_{3 / 2,1 / 2}$ states. E1ectric field strength was $700 \mathrm{~V} / \mathrm{cm}$. 


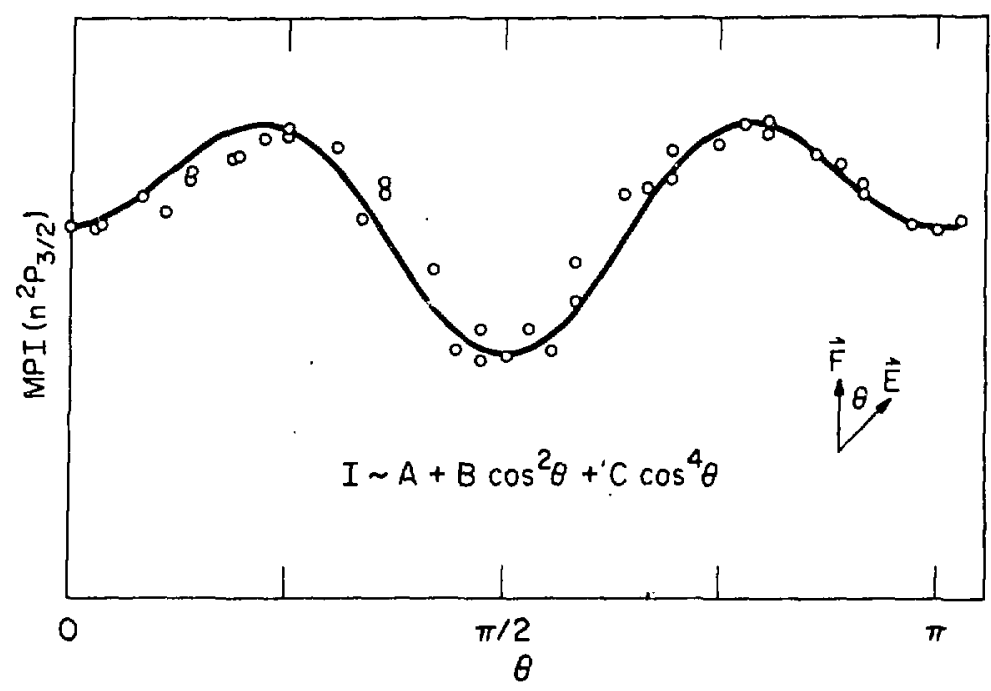

Fig. 11. Dependence of the field induced maltiphoton ionization signal due to the $\mathrm{np}^{2} \mathrm{P}_{3 / 2}$ state (see Fig. 9) as a function of the angle between the laser polarization $E$ and the electric field $\vec{F}$.

of complete Stark manifolds. Above the field-ionization limit we observe mach fine strncture, including some which persists to above the zero-field limit. Thus, anoply of phenomena, already known in one-photon spectroscopy, can be studied, often to good advantage, via VPI.

\section{CONCLUSIONS}

We have presented new cxperimental results on two- and threephoton ionization photoelectron angular distributions for an alkali atom. The results clearly illustrate the impor ance of hyperfine mixing at the resonant intermediate level. Section B presents the first experimental studies of the effects of static olectric fields upon SPI. The DC Stark effect is seen to induce ionization signels from electronic states which are normally absent due to symmetry selection rnles or low photolonization cross sections. Much further experimental and especially theoretical work needs to be performed on Stark effects on WPI. 


\section{REFERENCES}

[1] M. M. Lambropon1os and R. S. Berry, Phys. Rev. 8, 844 (1973).

[2] For reviows of various aspects of multiphoton ionization and photoelectron angular distribution see: P. Lambropodos in ADVANCES IN ATOMIC AND MOLECULAR PHYSICS 12, 87-164 (Acedemic Press, New York, 1976); MULTIPHOTON PROCESSES (J. H. Eberiy and P. Lambropoulos, Eds., Wiley, New York, 1978); and J. Horellec, D. Normands, G. Petite in ADVANCES IN ATOMIC AND MOLECULAR PIXSICS 18, 97-164 (Academic Press, New York, 1982).

[3] J. C. Tully, R. S. Berry, and R. J. Dalton, Phy s. Rev. 176, 95 (1968).

[4] S. N. Dixit and P. Lambroporlos, Phys. Rev. Lett. 46, 1278 (1981).

[5] S. N. Dizit and P. Lambropoulos, Phys. Rev. A 27, 168 (1983).

[6] J. A. Doncanson, Jr., M. P. Strand, A. Lindgrard, and R. $S$. Berry, Phy . Rov. Lett. 37, 987 (1976).

[7] J. C. Hangen, J. A. Duncanson, Jr., R.-L. Chien, and R. S. Berry, Phys. Rev. A 21, 222 (1980).

[8] S. Edelstein, M. M. Lambropodlos, and R. S. Berry, Phys. Rev. A 9, 2459 (1974).

[9] H. Kaminski, J. Kessler, and K. J. Kollath, Phys. Rev. Lett. 45, 1161 (1980).

[10] D. Foldmann and $\mathrm{K}$. H. Telge, J, Phys. B 15, 1651 (1982).

[11] G. Louchs and S. J. Smith, J. Phys. B 15, 1051 (1982).

[12] M. P. Strand, J. Hansen, R. -L. Chien, and R. S. Berry, Chem. Phys. Lett. 59, 205 (1978).

[13] G. Lenchs, S. J. Smith, E. Khawaja, and H. Walther, Optic Comm. 31, 313 (1979).

[14] F. Fabre, P. Agostini, G. Petite, end M. Clement, J. Phys, B 14, 1677 (1981).

[15] W. Ohmesorge, F. Diedrich, G. Lenchs, D. S. Elliott, H. Walther, Phys. Rov. 29, 1181 (1984).

[16] P. Agostini, F. Fabre, G. Mainfray, G. Petite, and N. K. Rahman, Phys. Rev. Lett. 42, 1127 (1979).

[17] See Richard R. Freeman, International Conference on Atomic Physics, 1980, in ATOKIC PHYSICS $Z$ (D. Kleppner and F. $M$. Pipkin, Eds.), Plenam Press, 1980.

[18] H. Kaminski, J. Kessler, and R. J. Kollath, Phys. Rev. Lett. 45, 1161 (1980).

[19] R. N. Compton, J.A.D. Stockdale, C. D. Cooper, X. Tang, and P. Lambropoulos, Phys. Rev. A (submitted).

[20] S. N. Dixit and P. Lambropoulos, Phys. Rer. A 27, 168 (1983),

[21] W. E. Cooke and T. F. Gallagher, Phys. Rev. A 17, 1226 (1978).

[22] E. Formi, Z. Physik $\underline{59}, 680$ (1929). 